\title{
Key factors affecting the future provision of tree-based forest ecosystem goods and services
}

\section{Journal Article}

\section{Author(s):}

Rasche, Livia; Fahse, Lorenz; Bugmann, Harald

Publication date:

2013-06

Permanent link:

https://doi.org/10.3929/ethz-b-000068344

Rights / license:

In Copyright - Non-Commercial Use Permitted

Originally published in:

Climatic Change 118(3-4), https://doi.org/10.1007/s10584-012-0664-5 


\title{
Key factors affecting the future provision of tree-based forest ecosystem goods and services
}

\author{
Livia Rasche $\cdot$ Lorenz Fahse $\cdot$ Harald Bugmann
}

Received: 2 November 2011 / Accepted: 11 December 2012 / Published online: 4 January 2013

(C) Springer Science+Business Media Dordrecht 2013

\begin{abstract}
The continuous provisioning of forest ecosystem goods and services (EGS) is of considerable interest to society. To provide insights on how much EGS provision will change with a changing climate and which factors will influence this change the most, we simulated forest stands on six climatically different sites in Central Europe under several scenarios of species diversity, management, and climate change. We evaluated the influence of these factors on the provision of a range of tree-based EGS, represented by harvested basal area, total biomass, stand diversity, and productivity. The most influential factor was species diversity, with diverse forest stands showing a lower sensitivity to climate change than monocultures. Management mainly influenced biomass, with the most intensively managed stands retaining more of their original biomass than others. All three climate-change scenarios yielded very similar results. We showed that (1) only few factor combinations perform worse under climatechange conditions than others, (2) diversity aspects are important for adaptive management measures, but for some indicators, management may be more important than diversity, and (3) at locations subject to increasing drought, the future provision of EGS may decrease regardless of the factor combination. This quantitative evaluation of the influence of different factors on changes in the provision of forest EGS with climate change represents an important step towards the design of more focused adaptation strategies and highlights key factors that should be considered in simulation studies under climate change.
\end{abstract}

Electronic supplementary material The online version of this article (doi:10.1007/s10584-012-0664-5) contains supplementary material, which is available to authorized users.

L. Rasche $\cdot$ L. Fahse $\cdot$ H. Bugmann

Forest Ecology, Institute of Terrestrial Ecosystems, Department of Environmental Sciences,

Swiss Federal Institute of Technology ETH, Universitätstrasse 22, 8092 Zürich, Switzerland

Present Address:

L. Rasche $(\bowtie)$

Research Unit Sustainability and Global Change, University Hamburg, Grindelberg 5,

20144 Hamburg, Germany

e-mail: livia.rasche@zmaw.de

Present Address:

L. Fahse

Institute of Mathematics, University Koblenz-Landau, Fortstrasse 1, 76829 Landau, Germany 


\section{Introduction}

Forests represent an important source of ecosystem goods and services (EGS). They contain $\sim 50 \%$ of the world's terrestrial carbon stock, provide habitat for more than $50 \%$ of the world's known terrestrial plant and animal species, deliver timber, and provide more than $75 \%$ of the world's freshwater from forested catchments (Shvidenko et al. 2005). Studies suggest that ecological processes in forests may be influenced strongly by a changing climate (e.g. Bonan 2008; Dale et al. 2010; Kirschbaum et al. 1996; Root et al. 2003), leading to changes in diversity (Hansen et al. 2001), composition, and productivity (Shugart et al. 2003) at the local scale. Many EGS are tied to these processes and characteristics; therefore, an assessment of the factors potentially undermining their provision is tied to an assessment of their sensitivity to climate change.

The sensitivity of forests to climate change is influenced by stand characteristics such as the "functional response diversity" (e.g., Elmqvist et al. 2003; Hooper et al. 2005) and a heterogeneous structure (Bodin and Wiman 2007). No management (Thompson et al. 2009) or forest management with a reduced intensity (Noss 2001) may positively influence sensitivity. The importance that scientists attribute to each of these factors varies and seems to depend on the desired utilization of the forests. For example, the maintenance of the protective function of mountain forests (Cordonnier et al. 2008) depends on other factors than a maximization of timber production (Nuutinen et al. 2006) or carbon (C) storage (Lasch et al. 2005).

Numerous publications on the effects of climate change on forest ecosystems (e.g. Dale et al. 2010; Huo et al. 2010; Lindner 2000) and on how to adapt to these changes (e.g. Badeck et al. 2005; Kellomäki et al. 2008; Noss 2001) focus on specific EGS, often in a specific region, and intend to provide practical suggestions for adaptation. Instead of trying to answer the question of how climate change will affect forest ecosystems, we tackled the questions of to what extent climate change will influence the provision of EGS, and whether the magnitude of the effect is significant. Furthermore, we aimed at determining which factor-species diversity or type of management - influenced the magnitude of the effect most and whether the decisive factors differed when different indicators were considered. Lastly, we assessed whether different scenarios of climate change lead to significantly different simulation results.

To address these questions, we conducted a simulation experiment in which we varied the factors species diversity and management intensity at climatically different sites and under different scenarios of climate change. We were thus able to quantify their influence on the provision of selected tree-based EGS. Although we only considered a subset of all possible forest EGS, our study represents an important step towards the design of reliable adaptation strategies. We identified those factors that should be targeted first, and highlighted factors that showed to be influential when projecting the development of forest EGS with climate change.

\section{Material and methods}

\subsection{Forest model}

We used the model FORCLIM (Bugmann 1996), which simulates forest dynamics on small $\left(800 \mathrm{~m}^{2}\right)$ patches of land. We simulated 200 patches to determine ecosystem properties on the stand scale. The submodels weather and water provide values for minimum winter temperature, growing season temperature, and soil moisture based on long-term monthly climate data and the soil water-holding capacity. In the submodel plant, these variables and 
light availability determine the establishment probabilities of new tree cohorts. A modification of the carbon budget approach of Moore (1989) was used to model tree growth: an optimal growth rate was adjusted based on environmental factors (light, available nitrogen, growing season temperature, soil moisture) and crown length. The resulting volume growth was allocated dynamically to height and diameter growth based on available light and the species' shade tolerance. Tree mortality is triggered by both an age-related and a stressinduced component. In the submodel management (Rasche et al. 2011), several silvicultural treatments are available, including thinning, cutting, and a continuous cover forestry method ("plentering")- - see sections 1.1 and 1.2 in the electronic supplementary material (ESM), and Bugmann (1996), Didion et al. (2009), and Rasche et al. (2012) for more details.

\subsection{Study sites}

We chose six European sites from a previously utilized environmental gradient (e.g. Bugmann and Solomon 2000; Didion et al. 2009; Rasche et al. 2012); they comprise a variety of elevations and drought conditions (subalpine to colline; Table 1). Climate data were obtained from the Landscape Dynamics Unit at the Swiss Federal Institute for Forest, Snow and Landscape Research (WSL); the DAYMET model (Thornton et al. 1997) was used to interpolate daily climate data to a resolution of 1 ha for 1930-2006 (see section 1.3, ESM). The other two site-specific parameters were adopted from the earlier studies.

\subsection{Types of management and levels of species diversity}

We simulated three types of management: no management (NO), plentering (PL), and ageclass forestry (AC). Management was performed at 10-year intervals. In age-class forestry, thinning intensity was set to $10 \%$ and trees were clear-cut at an age of 120 years-for detailed plentering settings see Table S1 in the ESM. The no-management and plentering simulations were spun-up for 1,500 years to ensure that the stands were in equilibrium with current climate. Age-class forestry simulations were spun-up for 80 years to allow stands to grow to the age typical of current Swiss forests. The same management was used in both the spin-up and the actual simulations.

We simulated three types of species diversity: forest stands with all 30 species parameterized for Europe in FORCLIM (ALL), stands consisting of only the 2-4 dominant species of the current potential natural vegetation (PNV), and monocultures (MONO) of the species

Table 1 Characteristics of the sites along an environmental gradient used in the study. Lat. latitude; Lon. longitude, Temp. long-term mean temperature; Prec. annual precipitation; $B S$ bucket size; and $A v N$ available nitrogen. Values were used in the FORCLIM model

\begin{tabular}{lccclclll}
\hline Site & $\begin{array}{l}\text { Lat. } \\
{\left[{ }^{\circ} \mathrm{N}\right]}\end{array}$ & $\begin{array}{c}\text { Lon. } \\
{\left[{ }^{\circ} \mathrm{E}\right]}\end{array}$ & $\begin{array}{l}\text { Elevation } \\
{[\mathrm{m} \text { a.s.1. }]}\end{array}$ & Altitudinal zone & $\begin{array}{l}\text { Temp. } \\
{\left[{ }^{\circ} \mathrm{C}\right]}\end{array}$ & $\begin{array}{l}\text { Prec. } \\
{[\mathrm{mm}]}\end{array}$ & $\begin{array}{l}\mathrm{BS} \\
{[\mathrm{cm}]}\end{array}$ & $\begin{array}{l}\text { AvN } \\
{\left[\mathrm{kg} \mathrm{ha}^{-1}\right]}\end{array}$ \\
\hline Bever & 46.6 & 9.9 & $\sim 1,710$ & Subalpine & 2.3 & 838 & 10 & 60 \\
Davos & 46.8 & 9.8 & $\sim 1,590$ & Subalpine & 3.0 & 1,030 & 10 & 60 \\
Adelboden & 46.5 & 7.6 & $\sim 1,320$ & Altimontane & 4.9 & 1,260 & 15 & 80 \\
Bern & 46.9 & 7.4 & $\sim 570$ & Submontane & 8.4 & 951 & 20 & 100 \\
Cottbus & 51.8 & 14.3 & $\sim 80$ & Colline & 8.5 & 535 & 24 & 60 \\
Basel & 47.5 & 7.6 & $\sim 320$ & Colline & 9.3 & 740 & 15 & 80 \\
\hline
\end{tabular}


currently most abundant at these locations (see Table S2, ESM). Regeneration was allowed to occur naturally but was restricted to the species of the respective diversity scenario.

\subsection{Climate change scenarios}

To represent the anticipated change in climate, we used spatially interpolated data from the Landscape Dynamics Unit at WSL. For this dataset (resolution $1 \mathrm{~km}$ ), three different regional climate models nested in the general circulation model ECHAM5 were used to derive climate data based on the IPCC (2007) AR4 scenario A1B, providing us with the alternatives KNMI, SMHI, and MPI (see section 1.5, ESM). We assumed that the changes in the climate proceed linearly over a period of 100 years from 2001 to 2100 and that climate remains constant thereafter until the end of the simulation in 2300.

\subsection{Indicators of EGS}

The Millennium Ecosystem Assessment report mentions four categories of EGS: provisioning, regulating, cultural, and supporting services (Hassan et al. 2005). From each of these categories, we chose one indicator that could be assessed with FORCLIM and deliberately narrowed the choices to those that could be estimated reliably by the model. This small number also ensured that we were able to assess each indicator individually, i.e. without having to aggregate results and thus possibly miss a signal.

For the provisioning services, we chose harvested basal area per hectare $\left(\mathrm{m}^{2} \mathrm{ha}^{-1} \mathrm{a}^{-1}\right)$, while for regulating services, we chose biomass per hectare $\left(\mathrm{t} \mathrm{ha}^{-1} \mathrm{a}^{-1}\right)$ to assess the potential for carbon storage and thus climate regulation. For the cultural services, we chose a stand diversity index (SDI; see section 1.6, ESM), representing the common perception that diverse forests are more aesthetically pleasing than even-aged stands (e.g. CarvalhoRibeiro and Lovett 2011). Lastly, for the supporting services that underpin the provision of all other ecosystem services, we chose productivity in terms of volume growth $\left(\mathrm{m}^{3} \mathrm{ha}^{-1} \mathrm{a}^{-1}\right)$.

\subsection{Simulation studies and statistical analyses}

To calculate the difference between the climate change and the corresponding non-climate change simulation of each scenario, i.e., the magnitude of change, we used a modified version of the similarity index of Whittaker (1952). In our version of the index ("relative semblance"), changes for the better (e.g., a higher productivity) result in positive values up to 1 , changes for the worse result in negative values down to -1 , and no change equals 0 (see section 1.7, ESM).

To compare the scenarios, i.e., unique combination of alternatives such as "ALL-NOKNMI", we first grouped the values based on the management type, then based on the species, and lastly based on the climate change scenario. The subgroups were then compared using a Kolmogorov-Smirnov test to assess whether one alternative yielded significantly different relative semblance values than another, and whether they significantly diverged from zero.

Other approaches to statistically analyze the results such as fitting linear models of generalized least squares directly to the time series of the indicators, were rejected because sigmoidal and other non-linear trends could not be accounted for and the different scenarios could not be compared to a reference state-for more information see section 1.8, ESM.

In the last step, we calculated correlation coefficients between the relative semblance values of all 162 simulations (6 sites and 27 scenarios per site) for each indicator and the simulated bioclimatic variables influencing tree growth in FORCLIM (minimum winter 
temperature, annual/seasonal degree days, and annual/seasonal drought index) to evaluate possible general patterns underlying the trends in relative semblance.

\subsection{Adaptive management scenarios}

At sites where a scenario performed significantly worse than other scenarios (relative semblance significantly $<0$ and below other scenarios), we created adaptive management measures that targeted the responsible factor. These measures concerned the species diversity factor "monoculture" at three sites, plentering at two sites, and age-class forestry at one site. Thus, monocultures were adapted by replacing the original species with a species more suitable for the changed climate, i.e., the dominant species in the ALL simulations with climate change; this replacement occurred after the first clear-cutting in age-class-forestry scenarios and gradually after the year 2000 in no-management and plentering scenarios. At sites where management was the decisive factor, thinning intensity was increased (see Table S4 ESM). Results of the adaptive management simulations were evaluated as described in the section 2.6.

\section{Results}

The three climate-change scenarios yielded nearly the same results; therefore, we present here only the scenario KNMI, whereas the management and species-diversity factors are evaluated in detail—for complete results see Table S5, ESM.

\subsection{Example of unprocessed results}

To facilitate the understanding of the aggregated results reported in the following, Fig. 1 shows two examples of the underlying unprocessed data (for more examples, see Fig. S2 ESM), specifically the development of species-specific basal areas in Davos and Basel and the changes in the four EGS indicators. Each indicator clearly responded to the effects of climate change, some in a more pronounced manner than others. Some indicators were also markedly influenced by the scenario considered-in Davos, for example, the climate-induced changes in SDI were much larger in highly diverse stands than in monocultures, resulting in relative semblance values $>0$ for the ALL scenario but near-zero values for the MONO scenario.

\subsection{Harvested basal area}

Total harvested basal area (Fig. 2a) increased in most scenarios in Bever (subalpine), Davos (subalpine), and Adelboden (altimontane), and decreased in most scenarios in Bern (submontane), Cottbus (colline), and Basel (colline). In Bever, scenarios with monocultures especially suffered losses, and the harvested basal area of both monocultures and potential natural vegetation stands declined below the levels of the year 2000 (baseline). In Davos, the harvested basal area rose above the baseline in all scenarios; increasing significantly more in very diverse stands than in stands with lower species numbers. In Adelboden, only in highly diverse stands did the harvest levels rise above the baseline; in the other scenarios they did not change significantly. In Bern, only monocultures retained the harvest level of the baseline, whereas the harvested basal area of stands with more than one species declined significantly. In 


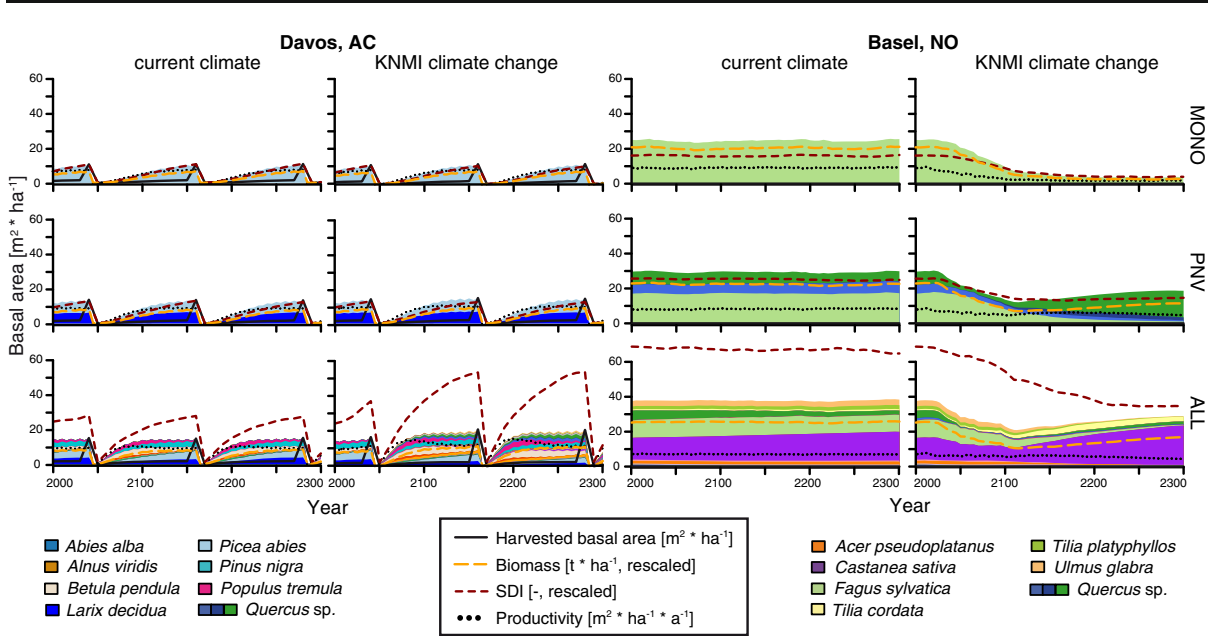

Fig. 1 Examples of the underlying data used for the calculation of relative semblance. Development of species basal area, harvested basal area, biomass, stand diversity, and productivity; on the left: Davos (management: age-class forestry), on the right: Basel (unmanaged). Top panels: monocultures; center panels: dominant species of the potential natural vegetation; bottom panels: all 30 species. The values of the indicators correspond to the y-axis scales, which have different units (see legend). The units of biomass and SDI were rescaled to fit the axis (biomass/10; SDI/100,000)

Cottbus and Basel, the harvested basal area in all scenarios declined significantly, and scenarios with plentering management were significantly lower.

\subsection{Biomass}

Only in Davos did the relative semblance of biomass stay near zero or rise to positive values in all scenarios (Fig. 2b). On all other sites, biomass declined relative to the baseline in most scenarios. In Bever, only the biomass of very diverse and age-class-managed stands fell below the baseline; all other scenarios yielded negative relative semblance values. In Adelboden, the biomass of unmanaged stands rose significantly above the baseline; other factors had no significant effect. In Bern, the biomass in all scenarios except those with ageclass forestry or monocultures fell below 0. In Cottbus and Basel, all scenarios performed worse than the baseline, with monocultures performing better than diverse stands in Cottbus and worse in Basel.

\subsection{SDI}

Stand diversity increased only in a few scenarios in Bever, Davos, and Adelboden, and decreased in all others (Fig. 2c). In Bever and Adelboden, the SDI of highly diverse stands increased, that of potential natural vegetation stands declined slightly, and that of monocultures declined strongly. In Davos, the SDI of highly diverse stands increased significantly compared to stands with a lower diversity and highly diverse stands were the only ones to rise significantly above the baseline. In Bern, the trend was reversed: only the SDI of monocultures did not differ significantly from the baseline, whereas the SDI of more diverse stands was lower and they performed significantly worse than monocultures. In Cottbus, the SDI of all scenarios declined 

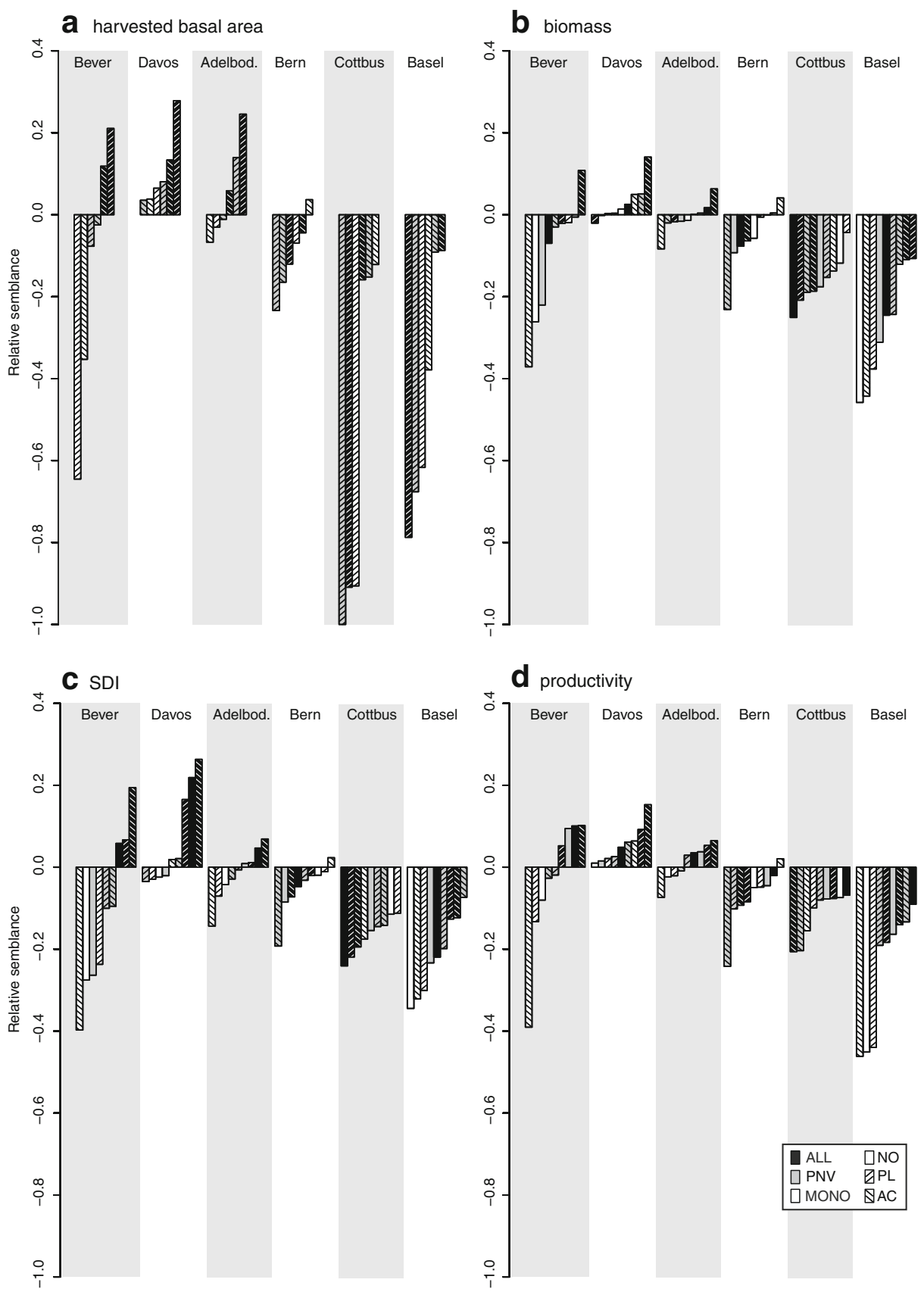

Fig. 2 Relative semblance values of each simulated management and species scenario at six different sites for the indicators a harvested basal area, b biomass, c SDI, and $\mathbf{d}$ wood productivity. Relative semblance was calculated from the indicator values in the simulation without climate change and the simulation with a climate change scenario, in this case KNMI (as shown in Fig. 1). Scenarios can be identified by their shading and pattern, e.g., a white bar with lines slanted downward from left to right is the scenario monoculture managed with age-class forestry. Zero-line: level in year 2000, corresponding to "no change" 
below the baseline but scenarios did not differ greatly among each other. In Basel, the SDI of stands with more than one species slightly declined compared to the baseline, with monocultures having a significantly stronger decline. SDI was not influenced significantly by the type of management.

\subsection{Productivity}

Productivity declined with climate change on most sites (Fig. 2d). In Bever and Adelboden, the productivity of highly diverse stands significantly increased and that of monocultures significantly decreased compared to the baseline. Highly diverse stands also had significantly higher relative semblance values than potential natural vegetation stands, which in turn had significantly higher values than monocultures.

In Davos, productivity uniformly rose significantly above the baseline, with very diverse stands showing the highest values. In Bern and Cottbus, the productivity of all scenarios decreased significantly below the baseline; however, scenarios did not differ between each other in Bern. In Cottbus, stands managed with age-class forestry performed significantly worse than the others. In Basel, productivity uniformly declined below the baseline, yet highly diverse and potential natural vegetation stands had significantly higher relative semblance values than monocultures.

\subsection{Adaptive management scenarios}

We singled out the factors identified as responsible for the worst results and devised adaptive management strategies (see section 2.7). For the indicator regarding harvested basal area, monocultures in Bever and plentering-managed stands in Cottbus and Basel were concerned; while monocultures in Basel corresponded to the the biomass indicator and monocultures in Bever, Adelboden, and Basel corresponded to the SDI indicator. Lastly, the productivity indicator concerned monocultures in Bever and Basel and stands managed with age-class forestry in Cottbus.

Most simulation results were positively influenced by adaptive management measures (Fig. 3). In Bever, the relative semblance of harvested basal area in monocultures rose significantly above the baseline and no longer differed significantly from the more diverse stands (Fig. 3a). In Cottbus and Basel, relative semblance values of harvested basal area increased with an increase in management intensity but did not reach the level of stands managed with age-class forestry.

In Basel, the relative semblance of biomass (Fig. 3b) and SDI (Fig. 3c) increased with adaptive management measures to the levels of the more diverse stands. In Bever and Adelboden, with adaptive management measures, relative semblance values of SDI rose significantly above the baseline, while values for productivity also improved. In Bever, with adaptive management measures, monocultures outperformed the more diverse stands, whereas in Basel, monocultures rose to the level of the more diverse stands. In Cottbus, however, where adaptive management measures targeted the management intensity, there was no improvement (Fig. 3d).

\subsection{Correlation of relative semblance to bioclimatic variables}

Relative semblance values of all indicators were significantly correlated to the change in seasonal drought index from current to future climate and consistently reached the highest values of adjusted $R^{2}$. The change in the annual degree-days and the annual 

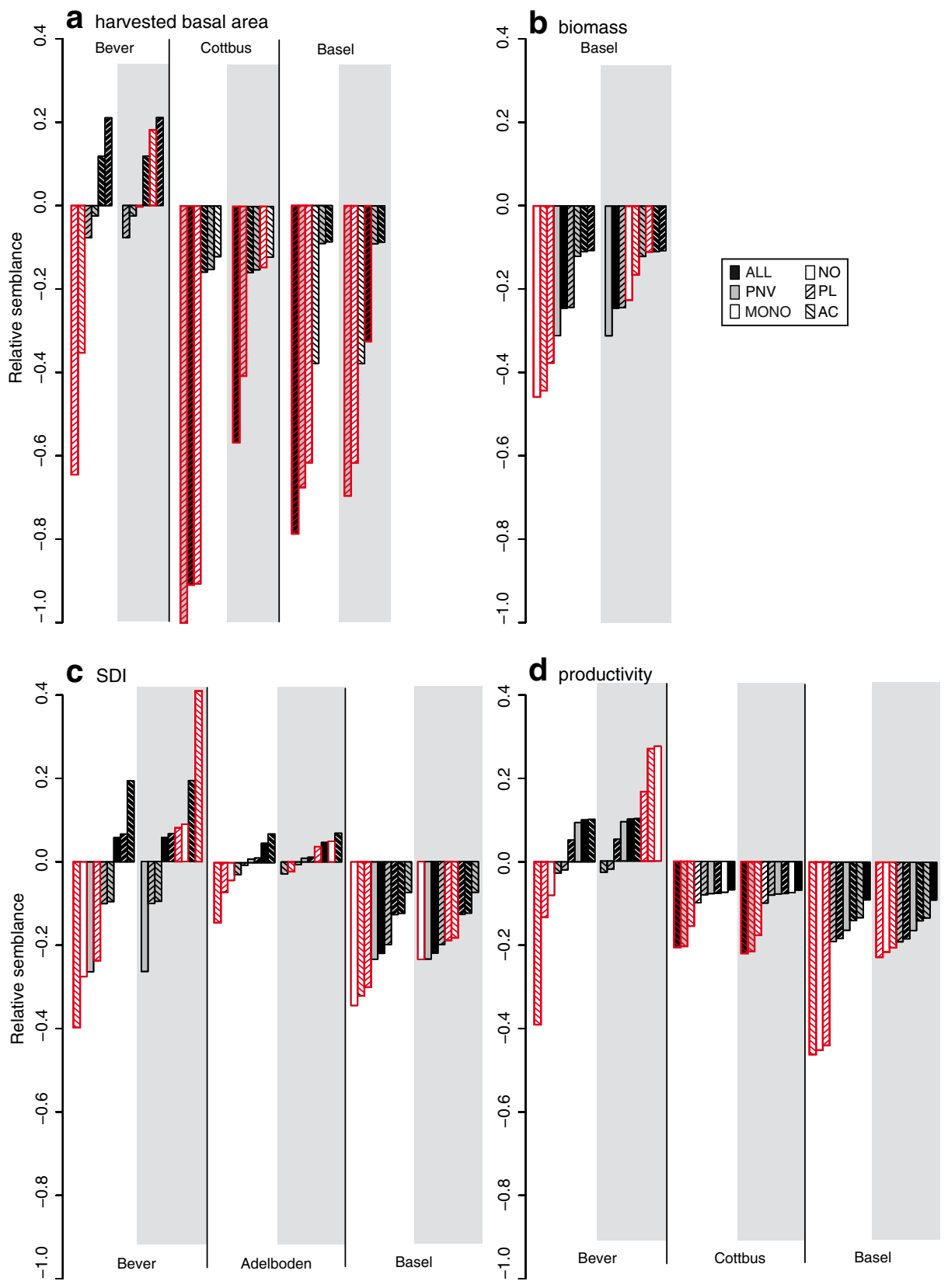

Fig. 3 Relative semblance values of the four indicators simulated with the original scenario setting (left, not shaded) and with an adaptive management setting (right, shaded). Only the scenarios responsible for the worst performance were adapted (red); the other scenarios remained unchanged (black). Scenarios can be identified by their shading and pattern (see Fig. 2)

drought index showed significant correlations for the values of all indicators except harvested basal area, whereas the change in seasonal degree-days showed a significant 
correlation only with that indicator. There was no significant correlation with minimum winter temperature (Fig. S3 ESM).

\section{Discussion}

The aim of our study was to systematically vary combinations of forest management, climate change, and species diversity to create a large database to statistically quantify the influence of each factor group. Two pervasive patterns emerged.

First, at subalpine and upper montane sites (Bever, Davos, Adelboden), the relative semblance tended to rise (indicating a higher harvested basal area, biomass, SDI, and productivity than without climate change), whereas at lower montane and colline sites (Bern, Cottbus, Basel), the relative semblance tended to fall, a result in agreement with the studies of Nabuurs et al. (2002), Loustau et al. (2005), Lexer and Seidl (2009), and Seidl et al. (2011). This pattern was linked to the magnitude of future drought, which is also in agreement with earlier studies (e.g. Ciais et al. 2005).

Second, the drier the location, the larger the variance in relative semblance values tended to be, implying that under optimal environmental conditions - as seen in Davos under future climate conditions - the scenario is unimportant. Under non-optimal conditions, sensitivity to climate change differed between scenarios, with the most influential factor being mainly species diversity.

\subsection{Key factors determining future EGS provision}

\subsubsection{Species diversity}

Species diversity significantly influenced SDI on all six sites, harvested basal area and productivity on four sites, and biomass on two sites. These results are in agreement with Díaz et al. (2005), who found that carbon sequestration and productivity, among others, are frequently affected by biodiversity. Field studies also have shown that productivity increases with biodiversity and often reaches an asymptote at high levels (Cardinale et al. 2007; Hooper et al. 2005), while Potvin and Gotelli (2008) have demonstrated a positive relationship between tree species richness and timber yield in tropical forests.

Loreau and Hector (2001) attributed such results to two types of effects: the "complementary effect" (i.e., inter-specific interactions or niche partitioning leads to a more efficient use of resources and thus to enhanced ecosystem function), and the "selection effect" (i.e., the higher the species number, the higher the probability that the most productive species is present). In a virtual experiment, Morin et al. (2011) identified the complementary effect as most influential, whereby forest gaps were filled faster when trees of different shadetolerance classes and growth potentials were present. The study did not consider climate change, but other authors have postulated that species traits together with drought resistance will determine the sensitivity of ecosystems in a changing climate (e.g. Díaz et al. 2005; Drever et al. 2006; Elmqvist et al. 2003; Hooper et al. 2005; Peterson et al. 1998).

Considering this, it is surprising that of the 16 cases where species diversity was the decisive factor in our study, only in 7 cases did monocultures actually perform significantly worse than more diverse stands. Cardinale et al. (2007), Jacob et al. (2010), and Morin et al. (2011) attribute such a result to the formation of monocultures by the most productive species under the specific environmental conditions. We observed this effect in Bever when we replaced Pinus cembra with Fagus sylvatica in adaptive management and improved the relative semblance of productivity beyond the level of more diverse stands. 
We conclude that for the indicators harvested basal area, SDI, and productivity, species diversity is the factor with the highest influence on the sensitivity to climate change. Yet, even though stands with more than one species retained higher levels of EGS on average, this was not always the case.

\subsubsection{Choice of management alternative}

Management significantly influenced the amount of harvested basal area under climate change at the warmer and drier sites of our climatic gradient (Cottbus, Basel). Age-classmanaged forests maintained higher harvesting levels than plentering-managed forests, even though both management types could not avert a decline to levels below the baseline. This difference was most likely due to plentering itself, in which trees are harvested only as long as the actual basal area is higher than that desired. With a decreased growing stock (in this case due to drought), constant harvesting levels could no longer be maintained. With adaptive management, we thus reduced the desired residual basal area, which led to an increase in relative semblance values. Whether this is a desirable course of action is debatable, as timber is usually of secondary importance to a stable stand structure in plentered forests, which often serve as protection against gravitational hazards (Ott et al. 1997), or are maintained for aesthetical reasons (recreation).

With regard to biomass, the choice of management was important mainly at the colder and wetter sites (Bever, Davos, Bern). In all three cases, age-class-managed stands retained more or increased their biomass more than unmanaged or plentering-managed stands. This difference is probably due to the fact that plentering stands are managed to keep the growing stock constant at all times, and unmanaged stands are not regularly disturbed to promote regeneration and growth, which suggests that management is of primary importance when biological carbon sequestration is a goal.

Unexpectedly, SDI was not influenced strongly by management. Even though species numbers were not controlled by management in our setting, at least vertical canopy structure should have been influenced. Stand thinning changes light conditions, and in FORCLIM, this leads to a change in the allocation of the volume increment in diameter and height growth. Climatic change apparently did not lead to large changes in the light profile of the simulated stands.

Overall, in comparison to other simulation studies - e.g., Eggers et al. (2008), Köhl et al. (2010), and Lindner (2000) - the influence of management on all indicators other than biomass was rather small in our study. The other studies, however, investigated other indicators such as changes in species composition - an indicator we did not use but which would have led to marked differences between age-class- and plentering-managed stands in highly diverse stands. Moreover, in practice, forest management usually controls the species composition of a stand, which would automatically make it the most influential factor (cf. Badeck et al. 2005; Lindner 2000).

\subsubsection{Choice of climate change scenario}

One factor that did not exert a significant influence on the change in EGS provision was the choice of the climate-change scenario. This may be caused by the small differences in temperature anomalies between the models. Eggers et al. (2008), for example, report noticeable differences in net annual biomass increment between the IPCC scenarios A1 and B1, whereas the differences produced under the scenarios A1, A2, and B2 were much smaller. Köhl et al. (2010) also reported little influence of either scenario A1B or B1 on 
timber volume and other stand characteristics in German forests and concluded that management had a far greater impact on forest development than the climate scenario. The field study of Kardol et al. (2010) arrived at a similar conclusion, although the authors stress the importance of stand type in contrast to climate variability as the main driver of change.

Based on our results, we would have to conclude that the choice of a specific scenario of climate change presents a minor source of uncertainty when simulating into the future. We are aware, however, that both the magnitude and the effects of climate change on climate variability and extremes are uncertain (Schär et al. 2004; Vidale et al. 2007), and that using scenarios with a higher trajectory of greenhouse gas concentrations and warming may lead to different results. A general conclusion about the importance of the choice of scenario is thus inappropriate.

\subsection{Adaptive forest management}

At four sites, we devised simple adaptive management strategies that targeted the factor with the most negative influence on the provision of EGS. In three cases, we targeted species diversity (monocultures) and replaced species with more-appropriate ones. In doing so, the semblance values of the monocultures reached the level of more diverse stands. Badeck et al. (2005) and Kellomäki et al. (2008) recommend similar adaptations for the retention of suitable levels of productivity. Another possibility would have been to introduce additional species, but we felt that this would have been inappropriate because monocultures will most likely form a part of mitigation strategies in the future (such as carbon sinks or convenient producers of renewable materials and fuels; FOREST EUROPE 2011).

When the age-class forestry or plentering management was the factor with the most negative influence, identifying the best adaptive management strategy was not straightforward. An increase in thinning intensity led to increased harvested basal area in Cottbus; however, productivity could not be improved. We conclude that other measures would have to be taken-e.g., the introduction of Mediterranean tree species. This also applies to locations where monocultures and diverse stands reached the same "bad" relative semblance values (e.g. Basel), and thus no adaptive management was applied. For a discussion of the methodology, see section 3 in ESM.

\section{Conclusions}

We found that the sensitivity to climate change in the context of the provision of EGS from forest stands ranged from nearly non-existent at subalpine-montane sites to high at colline sites, and mainly depended on the increase in seasonal drought. The most influential factor was species diversity, with monocultures usually being most sensitive to the impacts of climate change. The EGS provision increased significantly when the sensitive species was replaced by a climatically more suitable species early on. The change in biomass was influenced more by management than by species diversity, with age-class-managed stands retaining or increasing their biomass significantly more under climate change than under the other management approaches.

These findings are relevant for the planning of adaptive management measures, as they showed that (1) for projections of the provision of the range of EGS considered here, the choice of climate change scenario is almost arbitrary; (2) diversity deserves emphasis but may not always be the most important factor, and thus planning needs to be decided on a case-by-case basis; and (3) at locations subject to increasing drought, the provision of EGS may suffer in the future regardless of stand characteristics. 
This quantitative evaluation of the influence of different factors on changes in the provision of forest EGS with climate change represents an important step towards the design of more focused adaptation strategies and highlights factors that should be considered carefully in simulation studies of climate change.

Acknowledgements We thank Niklaus Zimmermann and Dirk Schmatz (WSL) for providing the climate change scenario data, Christof Bigler for suggestions on statistical analyses, and Xavier Morin and three anonymous reviewers for comments on the manuscript. This research was funded by the Swiss State Secretariat for Education and Research under COST Action FP0603.

\section{References}

Badeck FW, Fürstenau C, Lasch P, Suckow F, Peltola H, Garcia-Gonzalo J, Briceno-Elizondo E, Kellomäki S, Lexer MJ, Jäger D, Lindner M, Thiel D, Kaipanen T, Lehikoinen N, Junge S, Feliu J (2005) Adaptive management at the scale of management unit. In: Kellomäki S, Leinonen S (eds) Management of European forests under changing climatic conditions. University of Joensuu, Joensuu, Finland, pp 316-382

Bodin P, Wiman BLB (2007) The usefulness of stability concepts in forest management when coping with increasing climate uncertainties. Forest Ecol Manag 242:541-552

Bonan GB (2008) Forests and climate change: forcings, feedbacks, and the climate benefits of forests. Science $320: 1444$

Bugmann H (1996) A simplified forest model to study species composition along climate gradients. Ecology 77:2055-2074

Bugmann H, Solomon AM (2000) Explaining forest composition and biomass across multiple biogeographical regions. Ecol Appl 10:95-114

Cardinale BJ, Wright JP, Cadotte MW, Carroll IT, Hector A, Srivastava DS, Loreau M, Weis JJ (2007) Impacts of plant diversity on biomass production increase through time because of species complementarity. Proc Natl Acad Sci 104:18123

Carvalho-Ribeiro SM, Lovett A (2011) Is an attractive forest also considered well managed? Public preferences for forest cover and stand structure across a rural/urban gradient in northern Portugal. Forest Pol Econ 13:46-54

Ciais P, Reichstein M, Viovy N, Granier A, Ogee J, Allard V, Aubinet M, Buchmann N, Bernhofer C, Carrara A, Chevallier F, De Noblet N, Friend AD, Friedlingstein P, Grunwald T, Heinesch B, Keronen P, Knohl A, Krinner G, Loustau D, Manca G, Matteucci G, Miglietta F, Ourcival JM, Papale D, Pilegaard K, Rambal S, Seufert G, Soussana JF, Sanz MJ, Schulze ED, Vesala T, Valentini R (2005) Europe-wide reduction in primary productivity caused by the heat and drought in 2003. Nature 437:529-533

Cordonnier T, Courbaud B, Berger F, Franc A (2008) Permanence of resilience and protection efficiency in mountain Norway spruce forest stands: a simulation study. For Ecol Manag 256:347-354

Dale VH, Tharp ML, Lannom KO, Hodges DG (2010) Modeling transient response of forests to climate change. Sci Total Environ 408:1888-1901

Díaz S, Tilman D, Fargione J (2005) Biodiversity regulation of ecosystem services. In: Hassan RM, Scholes R, Ash N (eds) Ecosystems and human well-being: current state and trends, vol 1. Island, Washington, DC, pp 297-329

Didion M, Kupferschmid A, Zingg A, Fahse L, Bugmann H (2009) Gaining local accuracy while not losing generality: extending the range of gap model applications. Can J For Res 39:1092-1107

Drever CR, Peterson G, Messier C, Bergeron Y, Flannigan M (2006) Can forest management based on natural disturbances maintain ecological resilience? Can J For Res 36:2285-2299

Eggers J, Lindner M, Zudin S, Zaehle S, Liski J (2008) Impact of changing wood demand, climate and land use on European forest resources and carbon stocks during the 21st century. Glob Chang Biol 14:2288-2303

Elmqvist T, Folke C, Nyström M, Peterson G, Bengtsson J, Walker B, Norberg J (2003) Response diversity, ecosystem change, and resilience. Front Ecol Environ 1:488-494

FOREST EUROPE, UNECE, FAO (2011) State of Europe's forests 2011. Status and trends in sustainable forest management in Europe. Ministerial Conference on the Protection of Forests in Europe, Oslo, Norway, 14-16 June 2011

Hansen AJ, Neilson RP, Dale VH, Flather CH, Iverson LR, Currie DJ, Shafer S, Cook R, Bartlein PJ (2001) Global change in forests: responses of species, communities, and biomes. Bioscience 51:765-779 
Hassan RM, Scholes R, Ash N (eds) (2005) Current State and Trends. Millennium Ecosystems Assessment: Ecosystems and Human Well-being, vol 1. Island Press, Washington, DC, 917 pp

Hooper D, Chapin Iii F, Ewel J, Hector A, Inchausti P, Lavorel S, Lawton J, Lodge D, Loreau M, Naeem S (2005) Effects of biodiversity on ecosystem functioning: a consensus of current knowledge. Ecol Monogr 75:3-35

Huo C, Cheng G, Lu X, Fan J (2010) Simulating the effects of climate change on forest dynamics on Gongga Mountain, Southwest China. J For Res 15:176-185

IPCC (2007) Climate Change 2007: Synthesis report. Contributions of working groups I, II and III to the Fourth Assessment Report of the Intergovernmental Panel on Climate Change. in Pachauri RK, Reisinger A (eds.), IPCC, Geneva, Switzerland, p. 104

Jacob M, Leuschner C, Thomas FM (2010) Productivity of temperate broad-leaved forest stands differing in tree species diversity. Ann For Sci 67:503

Kardol P, Todd DE, Hanson PJ, Mulholland PJ (2010) Long-term successional forest dynamics: species and community responses to climatic variability. J Veg Sci 21:627-642

Kellomäki S, Peltola H, Nuutinen T, Korhonen KT, Strandman H (2008) Sensitivity of managed boreal forests in Finland to climate change, with implications for adaptive management. Phil Trans Roy Soc B Biol Sci 363:2339-2349

Kirschbaum M, Bullock P, Evans J, Goulding K, Jarvis P, Noble I, Rounsevell M, Sharkey T (1996) Ecophysiological, ecological and soil processes in terrestrial ecosystems: a primer on general concepts and relationships. In: Watson RT, Zinyowera MC, Moss RH (eds) Climate Change 1995. Impacts, adaptation and mitigation of climate change: scientific-technical analyses. Contribution of Working Group II to the Second Assessment Report of the IPCC. Cambridge University Press, Cambridge, pp 57-74

Köhl M, Hildebrandt R, Olschofksy K, Köhler R, Rötzer T, Mette T, Pretzsch H, Köthke M, Dieter M, Abiy M, Makeschin F, Kenter B (2010) Combating the effects of climatic change on forests by mitigation strategies. Carbon Balance Manag 5:8

Lasch P, Badeck FW, Suckow F, Lindner M, Mohr P (2005) Model-based analysis of management alternatives at stand and regional level in Brandenburg (Germany). For Ecol Manag 207:59-74

Lexer MJ, Seidl R (2009) Addressing biodiversity in a stakeholder-driven climate change vulnerability assessment of forest management. For Ecol Manag 258:S158-S167

Lindner M (2000) Developing adaptive forest management strategies to cope with climate change. Tree Physiol 20:299-307

Loreau M, Hector A (2001) Partitioning selection and complementarity in biodiversity experiments. Nature 412:72-76

Loustau D, Bosc A, Colin A, Ogée J, Davi H, François C, Dufrêne E, Déqué M, Cloppet E, Arrouays D (2005) Modeling climate change effects on the potential production of French plains forests at the subregional level. Tree Physiol 25:813-823

Moore AD (1989) On the maximum growth equation used in forest gap simulation models. Ecol Model 45:63-67

Morin X, Fahse L, Scherer-Lorenzen M, Bugmann H (2011) Tree species richness promotes productivity in temperate forests through strong complementarity between species. Ecol Lett 14(12):1211-1219

Nabuurs GJ, Pussinen A, Karjalainen T, Erhard M, Kramer K (2002) Stemwood volume increment changes in European forests due to climate change: a simulation study with the EFISCEN model. Glob Chang Biol 8:304-316

Noss RF (2001) Beyond Kyoto: forest management in a time of rapid climate change. Conserv Biol 15:578-590

Nuutinen T, Matala J, Hirvelä H, Härkönen K, Peltola H, Väisänen H, Kellomäki S (2006) Regionally optimized forest management under changing climate. Clim Chang 79:315-333

Ott E, Frehner M, Frey H-U, Lüscher P (1997) Gebirgsnadelwälder: Ein praxisorientierter Leitfaden für eine standortgerechte Waldbehandlung. Verlag Haupt, Bern, Switzerland

Peterson G, Allen CR, Holling CS (1998) Ecological resilience, biodiversity, and scale. Ecosystems 1:6-18

Potvin C, Gotelli NJ (2008) Biodiversity enhances individual performance but does not affect survivorship in tropical trees. Ecol Lett 11:217-223

Rasche L, Fahse L, Zingg A, Bugmann H (2011) Getting a virtual forester fit for the challenge of climatic change. J Appl Ecol 48:1174-1186

Rasche L, Fahse L, Zingg A, Bugmann H (2012) Enhancing gap model accuracy by modeling dynamic height growth and dynamic maximum tree height. Ecol Model 232:133-143

Root TL, Price JT, Hall KR, Schneider SH, Rosenzweig C, Pounds JA (2003) Fingerprints of global warming on wild animals and plants. Nature 421:57-60

Schär C, Vidale PL, Lüthi D, Frei C, Häberli C, Liniger MA, Appenzeller C (2004) The role of increasing temperature variability in European summer heatwaves. Nature 427:332-336

Seidl R, Rammer W, Lexer MJ (2011) Climate change vulnerability of sustainable forest management in the Eastern Alps. Climatic Change 106:225-254 
Shugart HH, Sedjo RA, Sohngen BL (2003) Forests and global climatecChange: potential impacts on US forest resources. Pew Center on Global Climate Change, Airlington, VA

Shvidenko A, Barber CV, Persson R (2005) Forest and woodland systems. In: Hassan RM, Scholes R, Ash N (eds) Ecosystems and human well-being: current state and trends, vol 1. Island, Washington, DC, pp 585-621

Thompson I, Mackey B, McNulty S, Mosseler A (2009) Forest resilience, biodiversity, and climate change: a synthesis of the biodiversity/resilience/stability relationship in forest ecosystems. Technical Series no. 43. Secretariat of the Convention on Biological Diversity, Montreal, $67 \mathrm{pp}$

Thornton PE, Running SW, White MA (1997) Generating surfaces of daily meteorological variables over large regions of complex terrain. J Hydrol 190:214-251

Vidale P, Lüthi D, Wegmann R, Schär C (2007) European summer climate variability in a heterogeneous multi-model ensemble. Clim Chang 81:209-232

Whittaker RH (1952) A study of summer foliage insect communities in the Great Smoky Mountains. Ecol Monogr 22:2-44 